\title{
Cognition, Ocular Accommodation, and Cardiovascular Function in Emmetropes and Late-Onset Myopes
}

\author{
Leon Nicholas Davies, James Stuart Wolffsobn, and Bernard Gilmartin
}

Purpose. To investigate objectively and noninvasively the role of cognitive demand on autonomic control of systemic cardiovascular and ocular accommodative responses in emmetropes and myopes of late-onset.

Methods. Sixteen subjects (10 men, 6 women) aged between 18 and 34 years (mean \pm SD: $22.6 \pm 4.4$ years), eight emmetropes (EMMs; mean spherical equivalent [MSE] refractive error \pm SD: $0.05 \pm 0.24 \mathrm{D})$ and eight with late-onset myopia (LOMs; MSE \pm SD: $-3.66 \pm 2.31 \mathrm{D}$ ) participated in the study. Subjects viewed stationary numerical digits monocularly within a Badal optical system (at both 0.0 and $-3.0 \mathrm{D}$ ) while performing a two-alternative, forced-choice paradigm that matched cognitive loading across subjects. Five individually matched cognitive levels of increasing difficulty were used in random order for each subject. Five 20-second, continuousobjective recordings of the accommodative response measured with an open-view infrared autorefractor were obtained for each cognitive level, whereas simultaneous measurement of heart rate was continuously recorded with a finger-mounted piezoelectric pulse transducer for 5 minutes. Fast Fourier transformation of cardiovascular function allowed the relative power of the autonomic components to be assessed in the frequency domain, whereas heart period gave an indication of the time-domain response.

REsults. Increasing the cognitive demand led to a significant reduction in the accommodative response in all subjects $(0.0$ D: by $-0.35 \pm 0.33 \mathrm{D} ;-3.0 \mathrm{D}$ : by $-0.31 \pm 0.40 \mathrm{D}, P<0.001)$. The greater lag of LOMs compared with EMMs was not significant $(P=0.07)$ at both distance $(0.38 \pm 0.35 \mathrm{D})$ and near $(0.14 \pm 0.42 \mathrm{D})$. Mean heart period reduced with increasing levels of workload $(P<0.0005)$. LOMs exhibited a relative elevation in sympathetic system activity compared to EMMs. Within refractive groups, however, accommodative shifts with increasing cognition correlated with parasympathetic activity ( $r=0.99, P<0.001)$, more than with sympathetic activity $(r=0.62, P>0.05)$.

Conclusions. In an equivalent workload paradigm, increasing cognitive demand caused a reduction in accommodative response that was attributable principally to a concurrent reduction in the relative power of the parasympathetic component of the autonomic nervous system (ANS). The disparity in ac-

From the Neurosciences Research Institute, School of Life and Health Sciences, Aston University, Birmingham, United Kingdom.

Presented in part at the British Congress of Optometry and Vision Science (BCOVS) in Birmingham, United Kingdom, December 2003.

Supported by a UK CASE Award 01800148 from the EPSRC (LND) and BAe Systems, United Kingdom.

Submitted for publication August 16, 2004; revised November 24, 2004, and January 4, 2005; accepted January 13, 2005.

Disclosure: L.N. Davies, None; J.S. Wolffsohn, None; B. Gilmartin, None

The publication costs of this article were defrayed in part by page charge payment. This article must therefore be marked "advertisement" in accordance with 18 U.S.C. $\$ 1734$ solely to indicate this fact.

Corresponding author: Leon Nicholas Davies, Neurosciences Research Institute, School of Life and Health Sciences, Aston University, Birmingham B4 7ET, UK; 1.n.davies@aston.ac.uk. commodative response between EMMs and LOMs, however, appears to be augmented by changes in the sympathetic nervous component of the systemic ANS. (Invest Ophthalmol Vis Sci. 2005;46:1791-1796) DOI:10.1167/iovs.04-0986

$\mathrm{O}$ ver the past 30 years much work has been undertaken to investigate the interaction between cognition and ocular accommodation. ${ }^{1-7}$ Some studies have shown, on exposure to cognitive tasks, a greater lag in accommodative response for high accommodative demand stimuli, ${ }^{8}$ whereas other studies show a greater lead in the accommodative response for near targets. $^{3,9}$ Investigators in previous studies have used a variety of paradigms to augment the cognitive demand such as counting backward in sevens, ${ }^{4,10}$ adding pairs of digits, ${ }^{2}$ and checking computations. ${ }^{6,7}$ The cognitive demand necessary to perform such tasks, however, is unlikely to be equivalent between individuals, varying with factors such as their mathematical ability and concentration. As such, comparison between investigations and between subject groups is both difficult and potentially misleading. Cognitive load is a complex paradigm and research has indicated that factors such as the method of presentation of the task, ${ }^{6}$ the nature of the processing task, ${ }^{10}$ and the distance at which it is presented ${ }^{8}$ may also influence the resultant accommodative response. In addition, account has to be taken of the effect of cognition on open-loop ${ }^{4}$ and closed-loop ${ }^{6}$ accommodation paradigms-the former being prone to large shifts in accommodative response, the latter being limited by ocular depth of focus.

Extensive investigation has identified differences in ocular accommodation between refractive groups, for example, amplitude of accommodation, ${ }^{11}$ tonic accommodation (TA), ${ }^{12}$ and the stimulus-response function. ${ }^{13}$ Variations in accommodative level during a cognitive task also vary with refractive error. Bullimore and Gilmartin 5 found that the imposition of a mental task induces a significantly greater positive shift in the TA of myopic than in that of emmetropic subjects. In a further study, ${ }^{4}$ the authors suggested that negative shifts (mean: $-0.04 \pm 0.03 \mathrm{D})$ seen in the accommodative response to a near $(-5.0 \mathrm{D})$ target during workload, were augmented by the sympathetic nervous system. Their hypothesis was supported when, using the $\beta$-antagonist timolol maleate, positive shifts (mean: $+0.04 \pm 0.01 \mathrm{D}$ ) in the accommodative response were observed for the same visual stimulus. ${ }^{8}$

The precise role of the autonomic nervous system (ANS) during cognitive tasks is also ambiguous. Cognitive demand or mental effort manifests itself in a variety of different forms, such as increased heart rate, vasodilation, and increased sweating. These changes are indicative of increased activity in the sympathetic branch of the ANS. ${ }^{3}$ Sympathetic activation serves to mobilize and prepare the body for action in response to stressor agents, objects of attention, and information being processed. ${ }^{14}$ These evolutionary reflexes are biologically effective in fight-or-flight situations, but may be detrimental when activated in response to a near task. Certain near visual tasks impose demands on the visual system inconsistent with its evolutionary purpose. Visual tasks require accurate accommodation, yet enforce concurrent demands for mental processing which appear to activate the sympathetic nervous system lead- 
ing to a reduction in the accommodative response. ${ }^{3,8}$ In practical terms, this mismatch between the innervation to accommodation and the required level may lead to diplopia, blur, and asthenopic symptoms. In turn, image blur may disrupt the emmetropization process, leading to the progression of myopia. ${ }^{15}$

The use of cardiovascular function to quantify the components of the ANS is an established methodology. ${ }^{16,17}$ Timedomain measures of heart rate variability (HRV) show that an increase in heart rate is initiated by an increase in the sympathetic nervous system. ${ }^{17}$ Such measures, however, are not sufficient to decipher the relative contributions of sympathetic and parasympathetic forces. The comprehensive review of HRV factors by the Task Force of The European Society of Cardiology and The North American Society of Pacing and Electrophysiology ${ }^{17}$ concluded that for short-term recordings (5 minutes), three main spectral components are distinguishable from the HRV trace: very low frequency, $<0.05 \mathrm{~Hz}$ (VLF); low frequency, from 0.05 to $0.15 \mathrm{~Hz}$ (LF, sympathetic component); and high frequency, from 0.15 to $0.40 \mathrm{~Hz}$ (HF, parasympathetic component). The LF and HF are not fixed parameters, but vary in association with manipulations of the ANS. The VLF component, however, is much less defined, and the precise physiological process attributable to these heart rate changes is questionable. Intuitively, one would assume that this frequency is a consequence of the DC component in the signal.

Measures of ocular accommodation appear to reflect neurologic brain activity and have been suggested to be a reliable objective index of information processing load. ${ }^{18}$ However, the few studies that have directly tested the proposition that autonomic factors are involved in augmenting the accommodative response during cognitive tasks have all used pharmacological agents, ${ }^{4,5,8}$ which in affecting the balance between the ANS components may not isolate the output of a single component in the normal environment.

Bullimore and Gilmartin ${ }^{8}$ suggested that stimulus distance is an important factor in determining the direction of the change in the accommodative response. As reported previously, the ciliary muscle is innervated by the dual actions of the sympathetic and parasympathetic branches of the ANS. ${ }^{19,20}$ The predominant parasympathetic system interacts with a supplementary sympathetic system. The principal features of sympathetic input are that it is inhibitory, relatively small (no more than $-2.0 \mathrm{D}$ ), and relatively slow. Time courses range between 20 and 40 seconds compared with the 1 or 2 seconds for the parasympathetic system. ${ }^{19}$ It appears that sympathetic activity is augmented by concurrent parasympathetic activity, so that the inhibitory effects of a given level of sympathetic innervation is enhanced by increasing levels of concurrent parasympathetic activity. Augmentation occurs on two counts: first, sympathetic inhibition becomes manifest only when there is something to inhibit, and hence there is a baseline requirement for concurrent parasympathetic activity. Second, parasympathetic activity above this level appears to augment sympathetic input directly but not to an extent greater than $-2.0 \mathrm{D}$, even at very high parasympathetic levels. ${ }^{19}$ Given this, it may be hypothesized that, for distant targets, mental effort has little effect (as sympathetic influences are minimal), whereas, for near targets, cognitive demand leads to a decrease in the accommodative response.

As near vision in modern visual environments often requires intensive periods of sustained processing of information, cognition is also believed to be an important factor in the association between near vision and myopia (particularly late-onset myopia $\left.{ }^{14,15,21}\right)$. The aim of this study was, therefore, to clarify the effect of cognition on accommodation in the context of both ocular and systemic (cardiovascular) autonomic control processes in EMMs and LOMs.

\section{Methods}

Sixteen subjects ( 10 men, 6 women) aged between 18 and 34 years (mean \pm SD: $22.3 \pm 4.6$ years) participated in the study. Eight were EMMs ( $\pm 0.25 \mathrm{D}$; mean spherical equivalent $[\mathrm{MSE}]$ refractive error \pm SD: $0.05 \pm 0.24 \mathrm{D})$ and 8 LOMs $(<-0.50 \mathrm{D} ;$ MSE: $-3.66 \pm 2.31 \mathrm{D})$. Subjects were considered LOMs when myopia onset was $\geq 15$ years of age. ${ }^{22}$ Subjects in both refractive groups were gender-matched (EMMs: five men and three women; LOMs: five men, three women). There was no significant difference in mean age between the two groups (EMMs: $22.1 \pm 4.4$ years; LOMs: $22.3 \pm 4.8$ years; unpaired $t$-test: $P=0.96$ ). To ensure that the accommodative demand was matched for each subject, all had visual acuity fully corrected with soft contact lenses (2-hydroxyethyl methacrylate [HEMA] lenses, 58\% water content; Acuvue Dailies, Vistakon; Johnson \& Johnson Vision Care, Jacksonville, FL). All subjects had $0.00 \log$ MAR distance visual acuity or better with an amplitude of accommodation $\geq 8.0 \mathrm{D}$, and uncorrected astigmatism was limited to $\leq 0.50$ DC. None of the subjects was taking any medication and none reported any form of visual or heart anomaly. All subjects had practice in remaining still and maintaining steady eye fixation to limit artifacts in both the heart period and accommodative data by participating in a trial run before the main study. Subjects were provided with a full explanation of the experimental protocol and gave written consent before commencing the investigation. The research followed the tenets of the Declaration of Helsinki and was approved by the Institutional Human Research Ethics Committee.

Subjects monocularly viewed stationary numerical digits between 1 and 100 (at both 0.0 and $-3.0 \mathrm{D}$ accommodative demand) through a Badal optical system (digit size: 6/9 Snellen equivalent; 80\% Michelson contrast), displayed on a $5 \times 4$-cm liquid crystal display (LCD) screen (luminance: $62 \mathrm{~cd} / \mathrm{m}^{2}$ ). Both target distance and digit presentation were randomized for each subject. The cognitive task consisted of a two-alternative, forced-choice paradigm, in which subjects were required to respond when the number presented was between 25 and 74 , inclusive. Subjects responded by pressing a hand-held Schmitt trigger connected to a computer (LabView software; National Instruments, Austin, TX), from which the response rates were calculated. At no point in the study did the subject have to change fixation. Cognitive demand was varied by altering the speed of presentation (between a 100- and 2000-ms delay) and calculating the correct response rate. Applying a Weibull curve-fitting function ${ }^{23}$ to these results, five individually determined, equivalent cognitive levels of increasing difficulty (corresponding to 0.1 second slower than $0 \%, 12.5 \%, 25 \%$, or $37.5 \%$ incorrect and 0.1 second faster than $50 \%$ incorrect) were determined and used in random order

Five 20-second continuous objective recordings of the accommodative response, measured with an open-view infrared autorefractor (Shin-Nippon SRW-5000; Ryusyo Industrial Co. Ltd, Osaka, Japan), were obtained for each of the five cognitive levels, whereas measurement of heart rate was recorded with a piezoelectric finger pulse transducer for 5 minutes, as suggested by the Task Force of The European Society of Cardiology and The North American Society of Pacing and Electrophysiology. ${ }^{17}$ To standardize the accommodation and cardiovascular measurements, accommodation was recorded in the first 20 seconds of each minute; thus, producing five accommodation epochs in the 5-minute cardiovascular recording period.

The infrared autorefractor was specially modified to record accommodative response continuously with a resolution of $<0.01 \mathrm{D}$ and a temporal resolution of $60 \mathrm{~Hz} \cdot{ }^{24}$ Data acquisition and analysis were performed on computer in the same software (LabView; National Instruments, Inc.). ${ }^{25}$ Any blink within the continuous sampling time causes an abrupt change in signal amplitude. ${ }^{26}$ Blinks were minimized within the 20-second measurement periods of accommodation so that only $1.4 \%$ of all data had to have blinks removed. Removal of these blink artifacts was performed as suggested previously by Wolffsohn et al. $^{27}$

Cardiovascular parameters were recorded with a piezoelectric pulse transducer (MLT 1010; UFI Instruments, Morro Bay, CA) attached 
Figure 1. Effect of cognitive demand on the accommodative error response for EMMs and LOMs at optical infinity (upper bars) and $-3.0 \mathrm{D}$ of accommodative demand (lower bars). Error bars, SEM; $n=8$ in each refractive group.

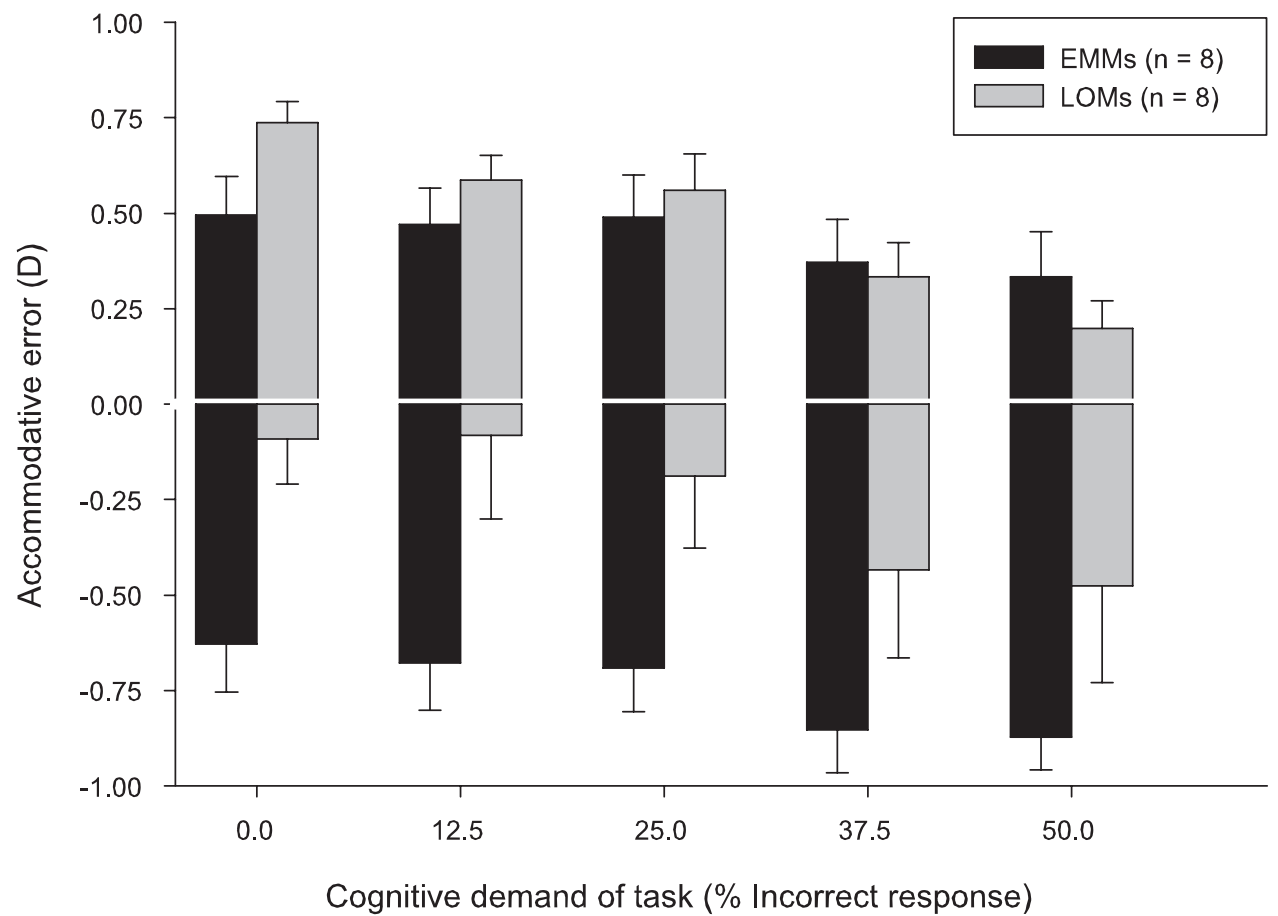

Fig. 1). The LOMs also showed a significant decrease (by $-0.54 \pm 0.25 \mathrm{D}$, for the $0.0 \mathrm{D}$ stimulus and by $-0.38 \pm 0.46$ $\mathrm{D}$, for the -3.0 D-stimulus; Fig. 1). Analysis indicated that the effect of cognitive demand $\left(\mathrm{F}_{(4.56)}=13.0 ; P<0.0005\right)$ was statistically significant. The difference between refractive groups $\left(\mathrm{F}_{(1,14)}=3.7 ; P=0.07\right)$ and the effect of accommodation demand was not significant $\left(\mathrm{F}_{(1,14)}=0.09 ; P=0.77\right)$.

\section{Cardiovascular Response}

Mean heart period showed a significant reduction $\left(\mathrm{F}_{(4,56)}=\right.$ 21.6; $P<0.0005$ ) with increasing levels of workload from the $0 \%$ to $50 \%$ incorrect cognitive level in all subjects (by $-0.05 \pm$ 0.02 second for the $0.0 \mathrm{D}$ stimulus and by $-0.05 \pm 0.02$ second for the $-3.0 \mathrm{D}$ stimulus) signifying an increase in systemic sympathetic innervation. Indeed, both refractive groups showed a significant reduction with increasing levels of workload (EMMs: by $-0.04 \pm 0.04$ second, for the $0.0 \mathrm{D}$ stimulus and by $-0.04 \pm 0.04$ second, for the $-3.0 \mathrm{D}$ stimulus; LOMs: by $-0.06 \pm 0.03$ second, for the $0.0 \mathrm{D}$ stimulus and by $-0.05 \pm 0.03$ second, for the $-3.0 \mathrm{D}$ stimulus; Fig. 2). There was no significant difference with stimulus vergence $\left(\mathrm{F}_{(1,14)}=\right.$ $1.7 ; P=0.21)$ or refractive error $\left(\mathrm{F}_{(1,14)}=1.3 ; P=0.27\right)$.

Fast Fourier transformation of the interheartbeat intervals in all subjects revealed two dominant frequency bands, as described previously. ${ }^{16,17}$ With increasing cognition, the LFC (sympathetic nervous system component) increased in power (by $0.35 \pm 0.27 \mathrm{~ms}^{2} / \mathrm{Hz}[0.12 \pm 0.18 \mathrm{n} . \mathrm{u}$.], for the $0.0 \mathrm{D}$ stimulus and by $0.37 \pm 0.32 \mathrm{~ms}^{2} / \mathrm{Hz}[0.12 \pm 0.16 \mathrm{NU}]$, for the $-3.0 \mathrm{D}$ stimulus $\left.\mathrm{F}_{(4,56)}=3.8, P<0.01\right)$, whereas the HFC (parasympathetic nervous system component) decreased in power (by $-0.31 \pm 0.24 \mathrm{~ms}^{2} / \mathrm{Hz}[-0.09 \pm 0.10 \mathrm{NU}]$, for the $0.0 \mathrm{D}$ stimulus and by $-0.33 \pm 0.32 \mathrm{~ms}^{2} / \mathrm{Hz}[-0.10 \pm 0.11$ $\mathrm{NU}$ ], for the $-3.0 \mathrm{D}$ stimulus; $\left.\mathrm{F}_{(4,56)}=3.1, P<0.05\right)$ in all subjects. The effect of target accommodative demand on the spectral components, however, was not statistically significant $\left(\mathrm{LFC}: \mathrm{F}_{(1,14)}=0.0, P=0.96\right.$; HFC: $\left.\mathrm{F}_{(1,14)}=1.8, P=0.20\right)$. LOMs exhibited a relative elevation of the LFC (sympathetic) over all cognitive levels compared with the EMM group $\left(F_{(1,14)}\right.$ $=6.0, P=0.03$ ) whereas, no significant difference occurred in 

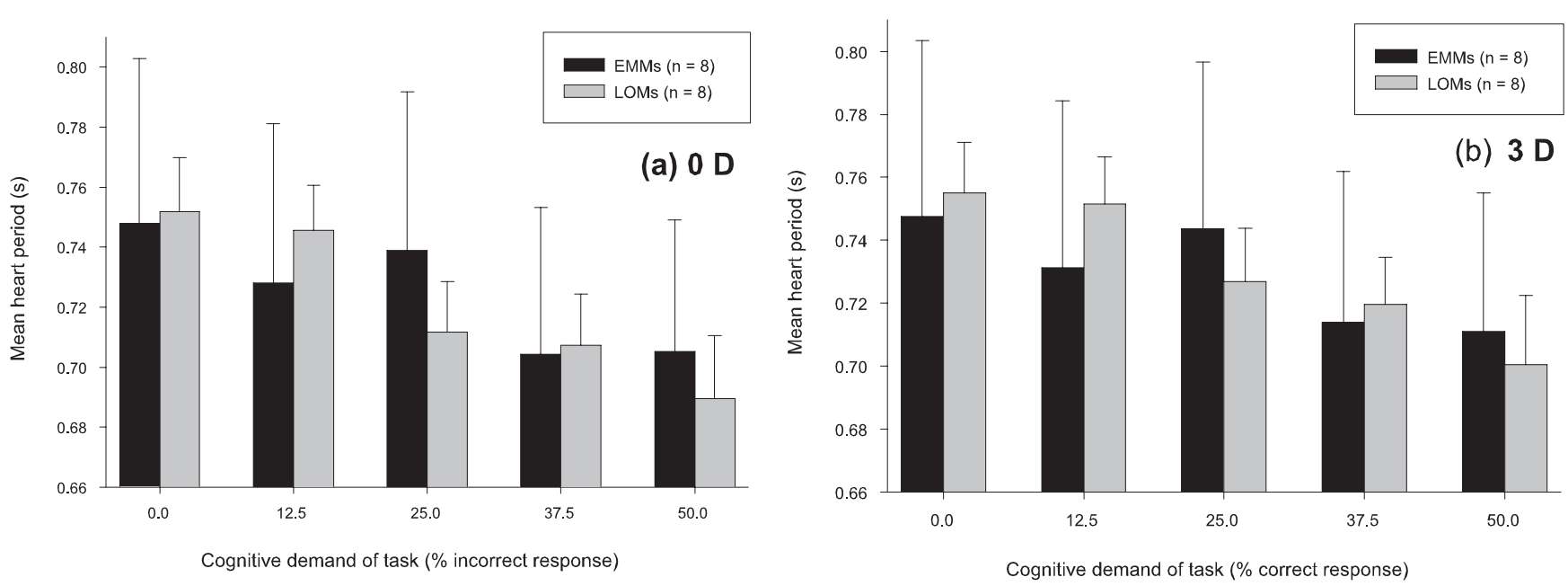

FigURE 2. Effect of cognitive demand on mean heart period for EMMs and LOMs at (a) optical infinity and (b) $-3.0 \mathrm{D}$ of accommodative demand. Error bars, \pm SEM; $n=8$ in each refractive group.

the HFC (parasympathetic) between the refractive groups $\left(\mathrm{F}_{(1,14)}=0.1, P=0.83\right.$; Fig. 3).

\section{Oculomotor and Cardiovascular Correlates}

Comparison of shifts in ocular accommodation with concurrent variations in cardiovascular function revealed a strong positive correlation between the mean accommodative response and mean heart period (0.0 D stimulus: $r=0.97, P<$ $0.005 ;-3.0 \mathrm{D}$ stimulus: $r=0.98, P<0.005)$. A strong positive correlation between mean accommodative response and mean heart period was also present in both EMMs $(r=0.95, P<$ 0.02 , for the $0.0 \mathrm{D}$ stimulus; $r=0.95, P<0.02$, for the -3.0
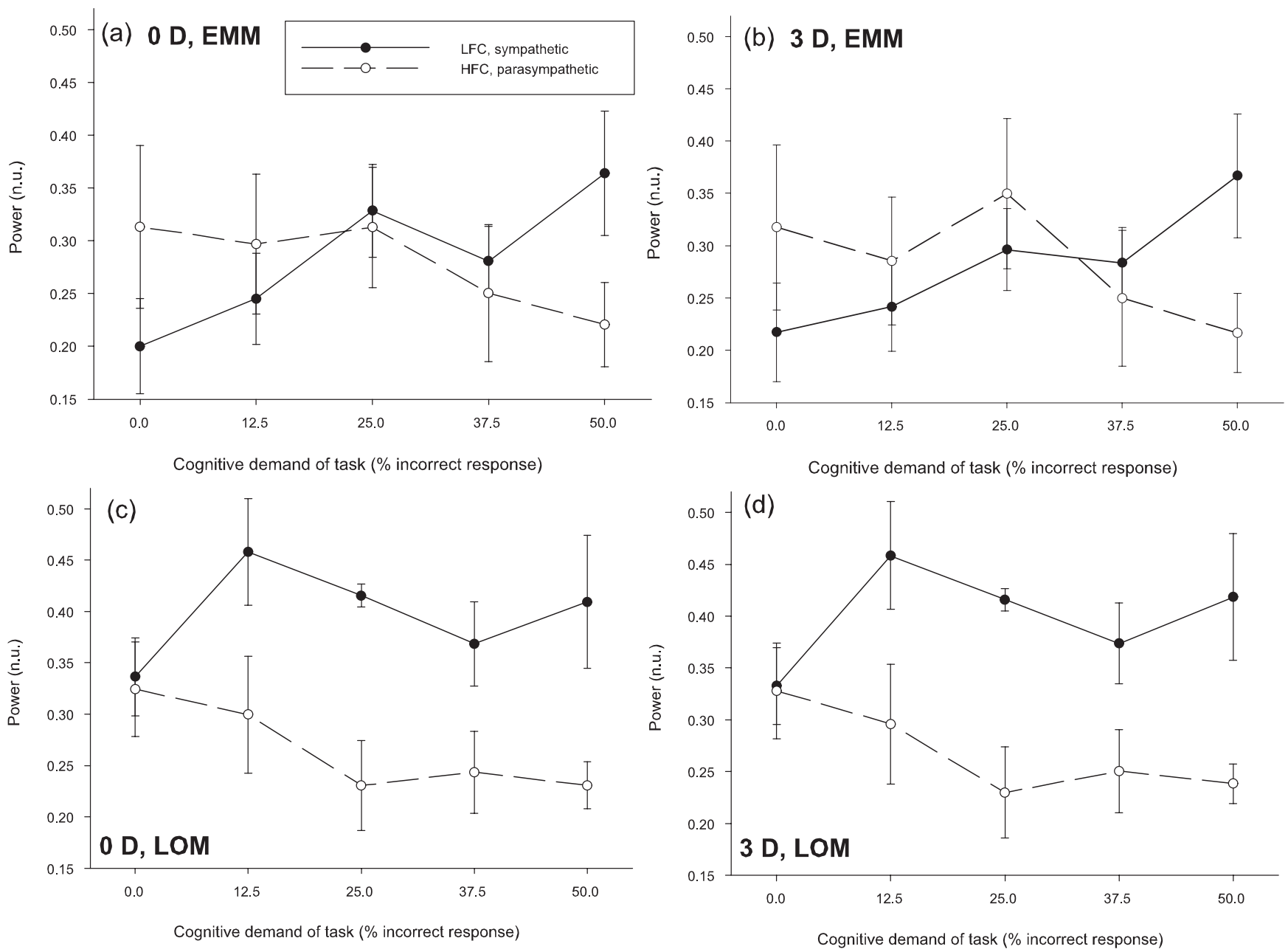

Figure 3. Effect of cognitive demand on the systemic sympathetic and parasympathetic autonomic profile in EMMs (a, b) and LOMs (c, d) at 0.0 and $-3.0 \mathrm{D}$ accommodative demand. Error bars represent $\pm \mathrm{SEM} ; n=8$ in each refractive group. 

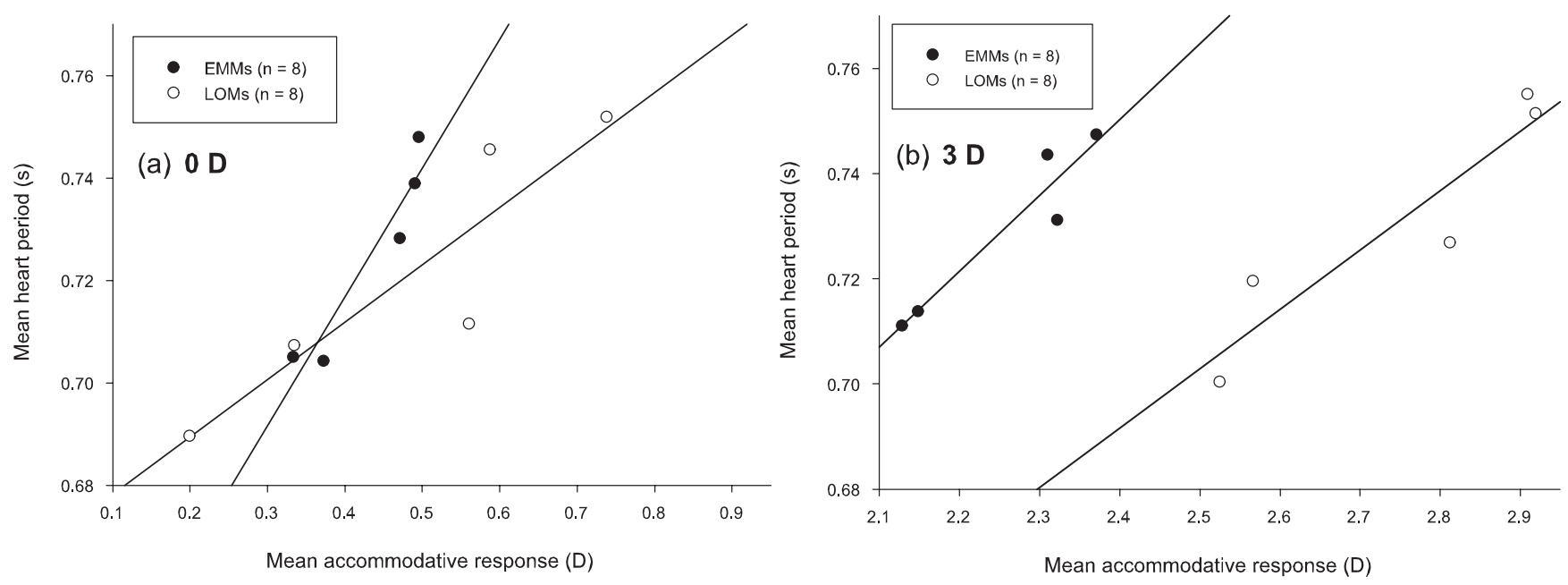

Figure 4. Correlation of mean accommodative response and mean heart period for EMMs and LOMs at (a) 0.0 and (b) $-3.0 \mathrm{D}$ accommodative demand. Each data point represents the mean value at each cognitive demand level. Error bars are omitted for clarity; $n=8$ in each refractive group.

D stimulus) and LOMs $(r=0.90, P<0.05$, for the $0.0 \mathrm{D}$ stimulus; $r=0.93, P<0.05$, for the $-3.0 \mathrm{D}$ stimulus; Fig. 4).

Across all subjects, the accommodative shift correlated with the parasympathetic autonomic innervation (HFC: $r=0.96$, $P<0.01$ for the $0.0 \mathrm{D}$ stimulus; $r=0.95, P<0.01$, for the $-3.0 \mathrm{D}$ stimulus). The correlation with the sympathetic response, however, was not as strong (LFC: $r=0.58, P>0.05$ for the $0.0 \mathrm{D}$ stimulus; $r=0.56, P>0.05$, for the $-3.0 \mathrm{D}$ stimulus) at both levels of accommodative demand examined.

The correlation between the accommodative shift and autonomic innervation was significant for the parasympathetic (HFC) component at optical infinity viewing, but not the sympathetic (LFC) component in LOMs (LFC, $r=0.62, P>0.05$; HFC, $r=0.99, P<0.001$ for the 0.0 D stimulus; LFC, $r=0.81$, $P>0.05$; HFC, $r=0.86, P>0.05$ for the $-3.0 \mathrm{D}$ stimulus), but neither component of the ANS correlated strongly with the accommodative shift with cognitive demand in the EMMs at both levels of accommodative demand (LFC, $r=0.17, P>$ 0.05 ; HFC, $r=0.77, P>0.05$ for the $0.0 \mathrm{D}$ stimulus; LFC, $r=$ $0.00, P>0.05$; HFC, $r=0.69, P>0.05$ for the $-3.0 \mathrm{D}$ stimulus).

\section{Discussion}

This study extends previous investigations ${ }^{1-7}$ by quantifying the ocular accommodation and cardiovascular responses to changes in cognitive demand at two stimulus vergences. The significant decrease in accommodative response from the low to the high cognitive demand condition (by approximately $1 / 3$ D) occurred despite constant retinotopic stimuli in a closedloop accommodative environment. It is well established that the accommodative response is determined by a complex interaction of retinotopic ${ }^{30,31}$ and spatiotopic ${ }^{7}$ factors. It has also been proposed that increased cognitive demand invokes a shift in the sympathetic input to the ciliary body. ${ }^{8}$ Bullimore and Gilmartin ${ }^{8}$ measured the closed-loop accommodative response in 12 EMMs at three accommodative stimulus levels $(-1.0,-3.0$, and $-5.0 \mathrm{D})$. Mental effort was shown to induce a significant increase in mean response for the $-1.0 \mathrm{D}$ task, a response equivalent to the passive condition for the $-3.0 \mathrm{D}$ task and a significant reduction in response for the $-5.0 \mathrm{D}$ task. Sympathetic blocking with timolol maleate affected only the accommodative response for the $-5.0 \mathrm{D}$ task, in that it was significantly increased.
In this study, however, the strongest correlation between the systemic autonomic nervous system and the accommodative response, within each refractive group, occurred for the parasympathetic system (accounting for between $47 \%$ and $99 \%$ of the variance). The systemic sympathetic system showed a weak nonsignificant correlation where only $0 \%$ to $65 \%$ of the variance in the autonomic branch was accounted for by the change in accommodative response within each refractive group. This suggests that the dominant factor in the retardation of the accommodative response is facilitated by the attenuation in the systemic parasympathetic innervation. The adaptive function of the ANS appears to reside principally in its sympathetic branch, as its structural organization is such that it provides integration and dissemination of responses according to need. In contrast, the parasympathetic branch has a more focal response profile. ${ }^{32}$ The results of this study appear to support this hypothesis.

Further evidence of the role of parasympathetic innervation in the cognitive response, lies with the "two-component model of attention" as suggested by Porges. ${ }^{33}$ In that study, physiological responses to attention could be divided into reactive and sustained components. These two components could be mediated by parasympathetic and sympathetic innervation. As such, responses to increased cognitive demand are augmented not only by sympathetic activity, but also by parasympathetic activity, a hypothesis that is again supported by this study.

In contrast, when considering the effect of refractive error on oculomotor and cardiovascular function, it is the sympathetic nervous system that appears to be the controlling factor. On average, LOMs showed more than twice the reduction in accommodative response as did EMMs (mean shift: $-0.46 \mathrm{D}$ vs. $-0.20 \mathrm{D})$. Although the difference between refractive groups did not reach significance, the results are intriguing when considered concurrently with the effect on the cardiovascular system. In that case, the LOM group showed a statistically significant increase in the systemic sympathetic innervation over all cognitive levels, whereas no change between refractive groups occurred in the parasympathetic system. The evidence suggests that discrepancies in the accommodative response between refractive groups are attributable to the increase in systemic sympathetic innervation in LOMs.

In conclusion, the data demonstrate a significant reduction in accommodative response with increasing cognitive demand that is predominantly attributable to a concurrent reduction in 
the relative power of the systemic parasympathetic nervous system. The disparity and accuracy of the accommodative response between refractive groups, however, appears to be attributable to changes in the sympathetic nervous system. The findings suggest that concomitant measures of cardiovascular function can provide systematic monitoring of the effect of cognition on the accommodative response.

\section{References}

1. Kruger PB. Changes in fundus reflex luminance with increased cognitive processing. Am J Optom Physiol Opt. 1977;54:445- 451.

2. Kruger PB. The effect of cognitive demand on accommodation. Am J Optom Physiol Opt. 1980;57:440 - 445.

3. Malmstrom FV, Randle RJ, Bendix JS, Weber RJ. The visual accommodation response during concurrent mental activity. Percept Psychophys. 1980;28:440-448.

4. Bullimore MA, Gilmartin B. Tonic accommodation, cognitive demand, and ciliary muscle innervation. Am J Optom Physiol Opt. 1987;64:45-50

5. Bullimore MA, Gilmartin B. Aspects of tonic accommodation in emmetropia and late-onset myopia. Am J Optom Physiol Opt. 1987;64:499-503.

6. Iwasaki T. Effects of a visual task with cognitive demand on dynamic and steady-state accommodation. Ophthalmic Physiol Opt. 1993;13:285-290

7. Wolffsohn JS, Gilmartin B, Thomas R, Mallen EAH. Refractive error, cognitive demand and nearwork-induced transient myopia. Curr Eye Res. 2003;27:363-370.

8. Bullimore MA, Gilmartin B. The accommodative response, refractive error and mental effort: 1 . The sympathetic nervous system. Doc Ophthalmol. 1988;69:385-397.

9. Winn B, Gilmartin B, Mortimer LC, Edwards NR. The effect of mental effort on open- and closed-loop accommodation. Ophthalmic Physiol Opt. 1991;11:335-339.

10. Post RB, Johnson CA, Owens DA. Does performance of tasks affect the resting focus of accommodation? Am J Optom Physiol Opt. 1985;62:533-537.

11. McBrien NA, Millodot M. Amplitude of accommodation and refractive error. Invest Ophthalmol Vis Sci. 1986;27:1187-1190.

12. McBrien NA, Millodot M. The relationship between tonic accommodation and refractive error. Invest Ophthalmol Vis Sci. 1987; 28:997-1004

13. McBrien NA, Millodot M. The effect of refractive error on accommodative response gradient. Ophthalmic Physiol Opt. 1986b;6: 145-149.

14. Birnbaum MH. Nearpoint visual stress: a physiological model. J Am Optom Ass. 1984;55:825-835.

15. Rosenfield M. Accommodation and myopia. In: Rosenfield M, Gilmartin B, eds. Myopia and Nearwork. London: ButterworthHeinemann; 1998:91-116.

16. Akselrod S, Gordon D, Ubel FA, Shannon DC, Barger AC, Cohen RJ. Power spectrum analysis of heart rate fluctuation: a quantitative probe of beat-to-beat cardiovascular control. Science. 1981;213: $220-222$.

17. Task Force of The European Society of Cardiology and The North American Society of Pacing and Electrophysiology. Heart rate variability: standards of measurement physiological interpretation and clinical use. Eur Heart J. 1996;17:354-381.

18. Rosenfield M, Ciuffreda KJ. Proximal and cognitively-induced accommodation. Opbthalmic Physiol Opt. 1990;10:252-256.

19. Gilmartin B. Autonomic correlates of near-vision in emmetropia and myopia. In: Rosenfield M, Gilmartin B, eds. Myopia and Nearwork. London: Butterworth-Heinemann; 1998:117-146.

20. Chen JC, Schmid KL, Brown B. The autonomic control of accommodation and implications for human myopia development: a review. Ophthalmic Physiol Opt. 2003;23:401-422.

21. van Alphen GWHM. Emmetropization in the primate eye. In: Buck GR, Widdows K, eds. Myopia and the Control of Eye Growth. Ciba Foundation Symposium No. 155. London: Wiley; 1990:115125.

22. Edwards MH. Myopia: definitions, classifications and economic implications. In: Rosenfield M, Gilmartin B, eds. Myopia and Nearwork. London: Butterworth-Heinemann; 1998:1-12.

23. Weibull W. A statistical distribution function of wide applicability. J App Mech. 1951:292-297.

24. Mallen EAH, Wolffsohn JS, Gilmartin B, Tsujimura S. Clinical evaluation of the Shin-Nippon SRW-5000 autorefractor in adults. $O p h$ thalmic Physiol Opt. 2001;21:101-107.

25. Wolffsohn JS, Gilmartin B, Mallen EAH, Tsujimura S. Continuous recording of accommodation and pupil size using the Shin-Nippon SRW-5000 autorefractor. Ophthalmic Physiol Opt. 2001;21:108113

26. Collins M, Davis B, Wood J. Microfluctuations of steady-state accommodation and the cardiopulmonary system. Vis Res. 1995;35: 2491-2502.

27. Wolffsohn JS, Gilmartin B, Li RW, et al. Nearwork-induced transient myopia in preadolescent Hong Kong Chinese. Invest Ophthalmol Vis Sci. 2003;44:2284-2289.

28. Davies LN, Wolffsohn JS, Gilmartin B. The influence of cognition on oculomotor and cardiovascular function (Abstract). Ophthalmic Physiol Opt. 2004;24:155.

29. Snedecor GW, Cochran WG. Statistical Methods. 7th ed. Ames, IA: The Iowa State University Press; 1980:369-375.

30. Gray LS, Gilmartin B, Winn B. Accommodation microfluctuations and pupil size during sustained viewing of visual display terminals. Ophthalmic Physiol Opt. 2000;20:5-10.

31. Seidel D, Gray LS, Heron G. Retinotopic accommodation responses in myopia. Invest Ophthalmol Vis Sci. 2003;44:1035-1041.

32. Hamill RW. In: Robertson D, Low PA, Polinsky RJ, eds. Primer on the Autonomic Nervous System. Academic Press; 1996:12-25.

33. Porges SW. Peripheral and neurochemical parallels of psychopathy: a psychophysiological model relating autonomic imbalance to hyperactivity, psychopathy, and autism. In: Reese HW, ed. Advances in Child Development and Behaviour. New York: Academic Press; 1976;11:36-65. 